\title{
Exploring Cross-Cultural Communication Courses in Media Literacy: Case Study of Using the University General Education Program "Citizen Journalism and Actions"
}

\author{
Huei Lan Wang ${ }^{1}$ \\ ${ }^{1}$ Department of Communication, Nan Hua University, Taiwan \\ Correspondence: Huei Lan Wang, Department of Communication, Nan Hua University, Taiwan. Tel: \\ 886-5-272-1001. E-mail: hlwang@nhu.edu.tw
}

Received: March 18, 2018

doi:10.5539/ies.v11n10p78
Accepted: June 8, $2018 \quad$ Online Published: September 27, 2018

URL: https://doi.org/10.5539/ies.v11n10p78

\begin{abstract}
Values are at the center of culture, the core of intercultural communication, and the chief element affecting communication between nations. Currently, educating students regarding appropriate cognitive attitudes and behaviors in intercultural communication, the basis for the acquisition of intercultural citizenship, has become a challenge for educators. This paper presents a case study of an intercultural communication curriculum where students participate in a new community and thereby understand the differences between reality and media representation of foreign immigrants. At the end of class, the concept of "access media" will be presented to train students on producing community videos that voice the reality they have experienced through the curriculum processes to which they have been exposed. This involves training students to take social action against media manipulation of stereotypical images of foreign immigrants. This case study demonstrates how an intercultural communication process of learning transforms students. The data include an analysis and evaluation of classroom observations, student and teacher diaries, questionnaires, and focus groups to explain how students' intercultural communication competence was developed and led to their acquiring intercultural citizenship qualities that include "action in the community," in this case publishing their own community video. The article concludes by explaining how intercultural theory plays a significant role in intercultural communication and relationship formation, and provides a guide to assist teachers in Taiwan develop pedagogy of literacy for general education.
\end{abstract}

Keywords: media literacy, critical pedagogy, critical consciousness, action

\section{Introduction}

\subsection{Background and Purpose}

At the 1992 International Media Literacy Conference, scholars in the related field defined media literacy education as: teaching citizens the ability to access, analyze, evaluate, and communicate messages, including attentiveness to news reports that distort the image of the underprivileged, and an understanding of the motives behind media representation. These abilities directly influence the foundation for building a good civil society, the formation of collective civic awareness, and our imagination of cultures and the world (Wober \& Gunter, 1988, p. 3). In the face of competitive pressure from globalization and vicious media competitions, instances of false exaggeration and distorted representation of the underprivileged occur incessantly. This raises the question of how to teach citizens literacy and the ability to identify and make critical judgements of media representation, an important topic in civic literacy education.

Since the publication of the Ministry of Education's "Policy White Paper on Media Literacy Education" in 2002, the implementation of open policies on cable television, and the popularization of the internet, media literacy education has begun to emphasize not only the development of students' ability to criticize, interpret, and reflect environment through an impact between teachers and students' life experience and the education and even communication studies have reached out to the community in recent years.

To incorporate the above ideas into media literacy education and echo two of the eight lifelong learning competencies (European Commission, 2004) - digital competence and interpersonal, cross-cultural, and social competence - this study integrated "empowering" and "liberating" with "local life experience/actions," to teach citizens media literacy, skills, and knowledge in cross-cultural communication. Thus, during their "actions," they 
can perceive the definitions and viewpoints produced by the interaction between a media-oriented society and cultures as well as their effects on the communicative style and social interaction patterns in Taiwan. By observing the similarities and differences in cross-ethnic cultural views and a cultural understanding of the others, students can reflect on their own life and cultural experience, thus realizing and contemplating the importance of cross-cultural empathy and respect. Hence, this study primarily explored students' cognition, attitude, and behavior regarding media and their cross-cultural communication competencies during the learning process. Their competencies included: 1) identification of media representation-perceive, question, and reflect; 2) cross-cultural communication competencies-realize, review, understand, and act; and 3) cognition, attitude, and behavior, or change, internalize, and actualize. These display a common theme-the awakening of civil society, transformation and practice of media representation competencies, and cross-cultural communication competencies.

Based on the above reasons, this study employed the case study method to actualize the concept of "local life experience/actions," displaying the correlation between techniques in media operation and competencies such as cross-cultural communication skills. Both quantitative and qualitative research methods were employed. Strategies in gathering and analyzing data included questionnaires, focus groups, classroom observation, and work review. The general education program "Citizen Journalism and Actions" of the private university where the researcher currently teaches, was utilized for practice and research. The program organized a group practice of citizen journalism from August 2015 to January 2016 revolving around news reports on new immigrants in Taiwan. During the process of conducting interviews and producing news, students' learning experience in cross-cultural communications and their cross-cultural understanding and communication competencies were examined.

\section{Literature Review}

As this study concerns topics such as media literacy and competencies in cross-cultural and digital production, the literature review will focus on revisiting relevant contemporary theories and empirical research outcomes.

\subsection{Design of Media Literacy Courses}

\subsubsection{On Media Literacy and Related Course Content}

Media refer to the tools for the functioning of symbols, serving as an outlet to depict images that guide the audience as subjects into a message's context. The subjects then create a perceived sense of belonging and identity, as well as an identity position as required by the message. Therefore, cultures are represented through media in the form of symbols, a process during which the subjective identity of the audience is also being constructed. Although a subject is constituted by ideologies, they exist for the purpose of interpellation by the subject. In fact, this mechanism of cultural representation that interprets the interactive relationships between the text and its receptors is an articulation of identities. During media representation, the audience is both the subject and the object of the receptive and interpretative processes. Therefore, "media literacy" is not only a kind of knowledge but also an ability to handle and process messages. When a program leads students outside classrooms and into actual society (media), they can deconstruct the ideological frameworks of media representation through first-hand experience and hands-on practice. As they "learn by doing," they can be liberated from the false consciousness embedded constantly in the audience's mind, and in turn, developing the audience's "perspicacity" in the exploration of the truth. Thus, the audience can learn to reject and destroy the definitions originating from media while acquiring powers that are highly regarded in media literacy-"subjective/holistic views" and "self-awareness/self-determination."

A review of domestic research related to media literacy indicates that these studies are primarily based on media literacy theories and teaching methods. The first stage of media literacy involves interpreting the traditional lecture method of teaching and incorporating teachers and students' numerous life experiences (Bazalgette, 1997; Brown, 1991, 1998; Buckingham, 1990; Consdiine \& Haley, 1999; Kubey, 1998; Masterman, 1980, 1985, 1997) to guide students from being a passive to an active audience. The Canadian Association for Media Education Organizations (CAMEO) in Ontario stated, "A media literate person is one who has an informed and critical understanding of the nature, techniques, and impact of mass media as well as the ability to produce mass media products." Meanwhile, empowerment-oriented media literacy education advocates the power of the people in the hope that media will treat the audience as citizens, while members of the audience will commit themselves to civil society, actively participating in public affairs. Thus, it not only assists citizens in developing deliberate thoughts but also aids the media in fulfilling its public, educational, and diversified role (Buckingham, 2003).

\subsection{Cross-Cultural Understanding and Communication Competencies}

To actualize society's action strength in media literacy, it has become an essential step in related current education 
to adopt the perspective of media representation and develop students' corresponding cognition and cross-cultural competencies.

\subsubsection{Identification of Media Representation}

In general, cross-cultural competencies refer to the abilities to communicate with other people. Such abilities can either be equipped at a young age, or developed based on environmental need and corresponding personal intentions. Students must be trained to learn from problems such as stereotypes, prejudice, and identification in media representation, and develop their understanding and interpretation. With critical judgements and reflections that are weighed elements in media literacy, students can perceive, question, and reflect on issues, gradually constructing a cross-cultural knowledge structure and initiating the awakening of civil consciousness. If a course can instruct the students explicitly in identifying the conversation patterns and related knowledge represented in media texts, it will definitely help them understand the relationship among meanings, positioning, subjectivity, and pleasure of texts. By discussing the conversation patterns of texts, it can guide students in interpreting them from different perspectives. It can even teach them to create their own understanding by deconstructing and reconstructing a text in case of conflicting contents (Chen, 2012). These must be the first steps in the development of cross-cultural competencies.

\subsubsection{Cross-Cultural Communication and Understanding Competencies}

The development of cross-cultural communication competencies can be facilitated through training in cross-cultural communication and intercultural conversations with communities having specific cultures or cultural languages (including a different ethnicity, nationality, religion, culture, and social sub-culture) (Safonova, 2014). Therefore, there are three dimensions to cross-cultural communication, one of which is the attitude or ability to understand and adapt to another person's cultural background as well as the illustration of open-mindedness, empathy, and flexibility. Another dimension is the knowledge or awareness of cultural diversity, different lifestyles among cultures, one's own cultural differences with another person, and one's own stereotypical ideas (Candel-Mora, 2015). During the cross-cultural course, the learner shifts from an "object" to a "subject." His/her subjective learning experience is also externalized from the classroom through discussions of perceiving, questioning, and reflecting his/her cross-cultural knowledge with the teacher's subjective experience. In special contexts during encounters between distinct individuals or groups, both parties maintain a respectful, empathetic, and cooperative attitude and learn about the other party's language, history, and culture through interactive role-playing. This process of enhancing cross-cultural understanding is a cross-cultural learning journey (Chen, 2003; Imel, 1998; Taylor \& Henao, 2006). Therefore, teachers are no longer the initiators but are coordinators. The students participate in first-hand encounters with people from distinct cultural backgrounds and learn to understand them through empathy, an element emphasized in media literacy.

\subsubsection{Cognition, Attitude, and Behavior}

Based on the awakening of consciousness mentioned above, Paulo (1989), a scholar in critical pedagogy, emphasized that the awakening involving students as the subjects must generate action; without action, any form of critical awakening would be insignificant. Therefore, by identifying the ability to reconstruct the perception of one's own culture and the cultures of other ethnic groups, and integrating this ability into life experience, students can influence media literacy and cross-cultural literacy in the following ways: 1) Cognition: an understanding of the differences in beliefs and behavior among different media and cultures; 2) Attitude: a respect for the differences among various cultural groups; and 3) Behavior: the ability to adjust practices in real life according to different cultures and counteract the media as a means to conduct social practice. Since the preceding form of an action is linked to critical consciousness, the greatest significance of media literacy education is to utilize the power from uniting the awakened consciousness with actions to exercise the critical practice of a civil society.

In terms of integrating cross-cultural and media literacy in practice, related competencies in media production have accentuated the definition of media literacy in this new era of internet information. Digital tools in particular have become the most useful tools for social practice. Whether these digital tools are employed to influence civic participation is a greater concern than the usage of tools themselves. The new strategy in media literacy education observes the problem of representation in mainstream media and employs digital tools to compare, verify, interpret, and make critical judgements systematically about related topics such as stigmatization or representation. Thus, under "a clear knowledge of the purpose," courses can not only focus on the media but also obtain access to media channels and utilize media contents as well as the digital competence embodied in local people (Liu, 2015). New media literacy courses with this strategy emphasize aspects, including topic examination, understanding, and critical judgements of media contents, determination of participation objective, and participation method and efficacy assessment. However, its most important purpose is for learners to utilize their 
own instrumental competencies to display skills related to media/citizenship. Through understanding the social context wherein one lives and the "learning by doing" process of hands-on experience, students can transform their digital competencies into purposeful civic participation and reinforce its significance in new media literacy.

This study employed the case study method to explore changes in students' learning experiences before commencing the course and after one strategic course semester in new media literacy, apart from the acquirement of digital tools skills in terms of "identification of media representation," "cross-cultural communication competencies," and "cognition, attitude, and behavior."

\section{Research Design and Method}

Regarding the above considerations, this study employed the case study method as the framework and the theory of cross-cultural and media literacy as the theoretical basis of the course design, complemented by the new media literacy teaching strategy proposed by Liu (2015). A workshop for the PeoPo Citizen Journalism Platform was utilized as the research setting. The study centered around a permanent general education course on media literacy organized by the researcher at Nanhua University. During the 18 weeks from August 1 to January 31, 2016, altogether 42 university students from years 1 to 4 who were enrolled in the course were selected as research targets. To encourage their participation, before the course began, the researcher established sufficient communication with the students, providing them more information regarding the course's fundamental concepts and operation strategies as well as the research flow. The students subsequently signed the research agreement.

\subsection{Design and Implementation of the Media Literacy and Cross-Cultural Literacy Course}

The first stage of planning and implementing the course was based on the researcher's experience in operating the PeoPo platform. The course framework pivoted on knowledge and contents in cross-cultural/media literacy. Moreover, the students were guided to undergo changes, as it was an important aspect of the course to encourage them to act on their own initiatives. Therefore, the teaching method design was adjusted based on Lai and Hong's (2005) experience and course outline and objectives, to ensure proximity to the life and learning experience of the research targets. The course objectives were: 1) acquiring the "identification of media representation" ability, 2) "cross-cultural communication competencies," 3) the ability to change "cognition, attitude, and behavior" concerning the topic of new immigrants, and 4) skills in media production such as telling stories with images, commanding digital tools with both filming and film editing functions, gaining access to media (like PeoPo and YouTube), and others. The researcher/instructor transformed these four core competencies into the sub-objectives of different modules, the topics of which had been devised as well (as shown in Table 1).

Table 1. Course objective and topics at each stage

\begin{tabular}{|c|c|c|}
\hline Course Objective (Core Competency) & & e Topics \\
\hline \multirow{4}{*}{$\begin{array}{l}\text { Stage 1) Acquiring the "identification of media representation" } \\
\text { ability }\end{array}$} & 1. & $\begin{array}{l}\text { Learning about the basic relationship between media-oriented } \\
\text { individuals and society in media }\end{array}$ \\
\hline & 2. & $\begin{array}{l}\text { Understanding definitions and viewpoints produced by the } \\
\text { interaction between media-oriented society and cultures }\end{array}$ \\
\hline & 3. & $\begin{array}{l}\text { Understanding the public's stereotypes and stigmatization of new } \\
\text { immigrants and other problems }\end{array}$ \\
\hline & 4. & $\begin{array}{l}\text { Analyzing the media presentation of ethnic groups and new } \\
\text { immigrants }\end{array}$ \\
\hline \multirow{6}{*}{ Stage 2) Obtaining "cross-cultural communication competencies" } & 1. & $\begin{array}{l}\text { Understanding the causes of immigration, common issues, } \\
\text { requirements, and other information of the new immigrants }\end{array}$ \\
\hline & 2. & $\begin{array}{l}\text { Learning the precautions and digital filming skills for interviewing } \\
\text { new immigrants }\end{array}$ \\
\hline & 3. & $\begin{array}{l}\text { Introducing DV cameras and mobile photography tools and } \\
\text { teaching how to operate them. Teaching composition in } \\
\text { photography/sound recording and photography skills with tools } \\
\text { and teaching assistant for group teaching }\end{array}$ \\
\hline & 4. & Learning about cross-cultural communication and interaction \\
\hline & 5. & Meeting local new immigrants in the field \\
\hline & 6. & Sense of identity and culture: self-positioning \\
\hline
\end{tabular}


1. Practicing field interviews, sharing the progress and problems encountered with one another and discussing problem-solving

2. Observing the communication patterns of foreign cultures

Stage 3) Developing the ability to change "cognition, attitude and behavior" concerning the topic of new immigrants;

3. Learning from actual experience of interacting with new immigrants

4. Understanding cultural differences and comparing them with own experience

5. Reflecting on cultural experience and sharing with the class

6. Conducting field interviews and observations

1. Searching for materials and contemplating the news angles

Stage 4) Learning skills in media production such as, telling stories with images, commanding digital tools with both filming and film editing functions, gaining access to media (like PeoPo and YouTube), and others

2. Learning writing skills about story structure and interview reports

3. Practicing editing skills

4. Learning skills in reporting via words and videos

5. Viewing and discussing the work of different groups

6. Putting the significance of media access into action (for example, making a copy for uploading)

Overall, the course used explanation, demonstration, group discussion, extra-curricular practices, and work creation, display, and viewing to render the students proficient in the production skills involved in the case study of new immigrants. Meanwhile, different parties including international community associations, cross-cultural experts, and a Vietnamese film director who is a new immigrant, were invited to deliver a speech on cross-cultural topics. Two sharing sessions were organized to establish students' skill in raising questions and providing feedback. The students conducted several interviews in groups, as well as continuous discussions on the news focus and angle of their interview materials with the teacher. They shared their thoughts regarding the planning and interviewing experience through PowerPoint slides. Subsequently, they began to write their scripts and, through continuous sharing and discussion with other groups, constantly made amendments based on the feedback. After completing the final draft, the groups began to work on final post-editing. Altogether 42 students were divided into five groups, producing five topics on new immigrants: "Rely on Yourselves," "Voice Your Own Thoughts," "A Life Full of Polymer Clay," "Becoming a Taiwanese: Let the Dreams Fly High," "Sie Mei-li from Indonesia," and "A French Person in Taiwan."

\subsection{Data Collection and Analysis}

During data collection, 1) assessment forms regarding the cross-cultural competency levels were collected as quantitative research data, with 42 and 34 valid copies returned at the beginning and the end of the semester, respectively. Both the initial and final forms were designed based on the research purposes of this study, with reference to the assessment method of cross-cultural competencies proposed by the Intercultural Competence Programme (ICP). The collected textual data included 2) the students' weekly reflective journals, 3) the transcripts of the focus group interviews conducted at the beginning and the end of the semester, and 4) the course evaluation questionnaires at the end of the semester. Eventually, this study employed thematic analysis to dissect, categorize, and compile the collected data, followed by the analysis of subject-related categories. Meanwhile, the data collection strategies of focus group interviews and work viewing were adopted with regard to the case study method. The students' participation experience and learning outcomes at different stages were recorded.

\subsubsection{Data Organization}

This study categorized the collected data by different natures. The initial and final assessment forms were integrated and encoded with the statistical software-Excel. The qualitative interview and textual information, including the weekly reflective journals, the transcripts of the focus group interviews at the beginning and the end of the semester, the course evaluation questionnaires at the end of the semester, and service learning reflection lists were also organized.

\subsubsection{Construction of Analytic Framework and Discussion}

The research divided media literacy into three parts-"identification of media representation," "cross-cultural communication competencies," and "changes in cognition, attitude, and behavior," for investigation and discussion. They were also utilized as a basis for designing the interview outlines, assessments, and questionnaires to understand the students' progress, changes, and development after the course in terms of these three key aspects. 


\subsubsection{Data Analysis}

For the quantitative part, after the questionnaires had been completed and collected, the researcher encoded and registered the data in the computer. For the valid samples of the assessment forms at the beginning and the end of the semester, the statistical software package SPSS19.0 was employed for a quantitative data analysis. The t-test was used as the statistical method to compare the differences between these initial and final assessment forms. Three research questions were discussed. First, is there any difference in the competencies regarding media representation before and after the media literacy course? Second, is there any difference in the cross-cultural communication competencies before and after the media literacy course? Third, is there any difference, concerning feelings, changes, and growth in the cognition, attitude, and behavior before and after the media literacy course?

As for the qualitative part, data were primarily gathered from observation, interviews, literature review, and other methods. Raw data were presented in the form of literature review for an in-depth description (Kau, 1996). During data analysis, this study adopted three stages of data coding namely, open, axial, and selective coding (Pan, 2003), as well as the thematic analysis method that locates the inherent meanings behind things and phenomena by employing general concepts such as controls, induction, and comparison (Miles \& Huberman, 1994). Owing to the diverse nature of the collected data, data triangulation was conducted with different data collection methods such as learning assessment and focus group interviews, to examine the consistency of the study. Analyst triangulation was also conducted. Both the assisting analysts and the researcher analyzed the data to improve the validity of this study (Mao \& Chang, 2006). The above methods corresponded with the research principle emphasized in this study, of connecting multiple sources of evidence that noticeably increased its validity and reliability (Yin, 2009).

\section{Analytical Results of Research Data}

\subsection{Differences "Before" and "After" the Course}

To investigate the influence of this course on the students, this study referred to data regarding cross-cultural competencies from the assessment forms collected at the beginning and the end of the semester. With time as the independent variable and average scores in each questionnaire as the dependent variables, the t-test and one-way analysis of variance test were employed to examine any difference in each aspect of media literacy before and after the course. The differences in the assessment forms before and after the course are enumerated in Table 2.

Table 2. T-test summary of the average scores in each part of the students' assessment forms before and after the course

\begin{tabular}{|c|c|c|c|c|c|}
\hline Part of the Assessment Form & Test Time & Average Scores & $\begin{array}{c}\text { No. of } \\
\text { Samples }\end{array}$ & $t$ & $\mathrm{P}$ \\
\hline \multirow{2}{*}{ Part 1: Competencies in media representation } & Before & 3.21 & 42 & \multirow{2}{*}{-2.949} & \multirow{2}{*}{$.004 *$} \\
\hline & After & 3.52 & 34 & & \\
\hline \multirow{2}{*}{ Part 2: Cross-cultural communication competencies } & Before & 3.35 & 42 & \multirow{2}{*}{-1.431} & \multirow{2}{*}{.157} \\
\hline & After & 3.47 & 34 & & \\
\hline \multirow{2}{*}{ Part 3: Changes in cognition, attitude, and behavior } & Before & 3.49 & 42 & \multirow{2}{*}{-3.160} & \multirow{2}{*}{$.002 *$} \\
\hline & After & 3.83 & 34 & & \\
\hline \multirow{2}{*}{ Overall assessment form } & Before & 3.35 & 42 & \multirow{2}{*}{-2.878} & \multirow{2}{*}{$.005^{*}$} \\
\hline & After & 3.60 & 34 & & \\
\hline
\end{tabular}

As displayed in Table 2, the differences in "competencies regarding media representation," "changes in cognition, attitude, and behavior," and the overall assessment forms before and after the course indicate that the media literacy course significantly improved students' competencies in media representation and their cognition, attitude, and behavior.

\subsection{Changes "After" the Course}

This study understood and interpreted the data with thematic analysis to locate the internal perspectives of the course participants and reveal how their cognition, attitude, and behavior regarding media and their cross-cultural communication competencies transformed during the learning process. Three main themes are listed below: (1) identification of media representation, i.e., perceive, question, and reflect; 2) cross-cultural communication competencies, i.e., realize, review, understand, and act; 3) changes in cognition, attitude, and behavior, or internalize and actualize; and 4) display of a common theme: the awakening of the civil society, or transformation and practice of media representation competencies, and cross-cultural communication competencies. They are 
elaborated below:

4.3 Identification of Media Representation: Perceive, Question, and Reflect

4.3.1 The Intangible yet Pervasive Influence of the Media

- Intangible Effects of the Media on One's Own Values

Since I was a child, I have had a daily exposure to the news media, so I've been educated by it subconsciously. It has been teaching me what is right and wrong. A09221603

Actually, the media has influenced me significantly. For example, if it reports a scandal of some political figure, after seeing the news, whether it's true or not, it'll still certainly affect my thoughts. A09221402

- The Pervasive Effects of the Media on Social Values

It's true for most people in developed countries, but not entirely true for third world countries. Sometimes, the media also displays this kind of discrimination intangibly. Some people may feel discriminated against when the media aren't careful enough in their news reports. A10200203

- Image Distortion in the Media Leads to Misunderstandings and Conflicts in Society

I have a strong reaction to toothpaste commercials. It's too inappropriate to neglect someone's inner thoughts because of his/her appearance or skin color. This not only hurts the person's feelings but also harms ourselves. A10133602

4.3.2 Slackening Way of Thinking and Questioning and Judging the Media

- $\quad$ Remaining Skeptical Towards News Media

Know more about the news that is reported every day. Then I'll be more discerning in identifying false news...I can't say too clearly right now, but at least I won't trust everything blindly. A10064003

I've understood that the news is not completely reliable. Different channels will stress the different perspectives of a single news item. When I look at something now, even if it's a current fact, I'll still doubt it. A09220303

- $\quad$ Realizing the Lies in the Media

The election part has left a strong impression on me because until today I did not realize the media is so deceiving. A09221602

- $\quad$ Recognizing the Right of Supervising the Media

I have a deeper understanding of my influence as a citizen. At first, I felt a bit surprised. Then, I felt like I was awakened. A09220102

- Acknowledging the Necessity of Individual Judgements of the Media

Nowadays, the media grasp the public's attention by distortion and exaggeration. That is why we must learn to discriminate between right and wrong... and hold our own opinions and thoughts. A09223101

There are both good and bad media. The audience needs to make a choice between what to accept and what to reject. A09223802

4.3.3 Identifying and Reflecting on the Media's Opinions on Different Ethnic Groups

- Identifying the Media's Stereotypes of Certain Ethnic Groups

Black people or Africans or African Americans in movies shown on television, or in TV series, are the underprivileged. They are poor even though they commit crimes all the time...Because of these movies and TV series many people conclude that this is what black people are like. A10133103

- Refuting and Making Critical Judgements on the Media's Negative Opinions on Certain Ethnic Groups

When I was small, two thirds of my classmates were children of foreign couples... Often, there would be news about a foreign spouse who murders her husband for money, or who cannot stand it anymore and escape to her motherland. But that is not what I saw. Those foreign moms gave everything for their families, and were gentle with their husbands and children. A10130103

At the time when she was standing in the corridor, a foreigner was sitting next to her. Without a word, he reached out his hands and helped her carry the luggage. At first, the woman thought he was going to snatch it away. But he said that there was space left on his shelf and he moved her luggage onto the 
shelf where there was an empty space. D01050601

The first focus is the changes in participants' ability to identify media presentation during their learning experience. They changed from being surprised at the intangible effects of the media on personal values, to understanding how the media influences society pervasively and how they may even result in the public's misunderstanding of various ethnic groups, provoking conflicts. That was when the students started to lose their original thinking about the media. They went from accepting media messages habitually, to gradually questioning the authenticity of these messages. After observing numerous actual examples of erroneous news in the media, they realized the truth and began to build their own set of standards in viewing the media, in turn developing individual judgements. Simultaneously, they began to reflect on the media and found that it influences the public's stereotypes of different ethnic groups. Through their own experiences and judgements, they refuted and critically assessed the media's negative stereotypical impressions about certain ethnic groups.

4.4 Cross-Cultural Communication Competencies: Realize, Review, Understand, and Act

4.4.1 Realizing and Understanding the Values of Oneself, Society, and Different Cultures

- Realizing the Value Differences Between Oneself and Other People

As ethnic Chinese, why do we need to make small distinctions among us? Chinese and Taiwanese people were born from the same root. Why are we so desperate to attack each other? We are all separate individuals. Why can't we respect, embrace, and work with one another? A10133202

I have learnt how my values differ from those of other people. A09220101

- Realizing One's Own Bias Against Certain Ethnic Groups

Although we tend to think we do not discriminate against new immigrants, we may often take a discriminating attitude implicitly through our movements, languages, or looks. A10200202

I think I am biased. Because most foreign people I have been in contact with are caretakers, either parents or nurses, but I am still not very fond of those foreign workers at the factories. D01051002

- Realizing Society's Bias Against Certain Ethnic Groups

As we recently said, people from countries that have a more negative image may be workers, foreign laborers, but you have never seen a Japanese working as a domestic helper, have you? We may tend to look down on those who do more manual-intensive work. D09211501

I know an aboriginal student myself. Judging by his look, I cannot tell his difference from the rest of us. All kinds of policies and privileges have added up to the aborigines' constant exposure to news media. It is inevitable that other people will develop jealousy or negative impressions about them. A10130703

- Understanding the Unspoken Thoughts of Different Ethnic Groups

The story shown in the video made me heart-broken, but it also left a strong impression on me...They face challenges and struggle for a living and for their children. They work hard to become better persons in the future. A11240602

4.4.2 Reviewing and Adjusting One's Own Viewpoints with An Open Mind

- Being Able to Adjust One's Own Viewpoints Based on Interaction and Information

I had a friend in high school, whose mother is a Mainlander...She was hospitable and nice to everyone, not rude at all...remotely different from the impressions of the Mainlanders shown in the news. A10131403

During the interview process, I learnt more about the new inhabitants. They are actually hardworking. The Chairperson spoke up for them on her own. Their effort is really something from which we should learn. A11101303

From every sister's story, although they do not have a perfect life in Taiwan, we can still see their life conditions improve after hard work. It was really touching to see that they did not give up on themselves. A11240902

- Being Able to Adopt Different Perspectives

My classmates' presentation gave me more knowledge about new inhabitants, including the difficulties they encountered in Taiwan and the discrimination they experienced. I have always thought that we must be receptive to them, rather than give them strange looks. A11102302 
4.4.3 Good Knowledge of Oneself and Other People is the Foundation for Cross-cultural Communication

- Understanding that Different Cultures Have Different Ways of Communication and Expression

There is a huge contrast in expression and behavior among different cultures, out of which various distinct meanings can be interpreted. Numerous differences lie not only in actions but also in languages and words. A11031701

- Building a Strong Communication Foundation with Acceptance, Empathy, and Mutual Understanding

During human communication, misunderstandings arise from cultural or habitual issues. To avoid conflicts, we must be inclusive and know how to be silent and listen to others appropriately. A11031603

In face of different ethnic groups and cultures, we must keep an inclusive, forgiving mind and try to accept people and cultures that are different from us. Learn from the good things about them; treat the bad things as a lesson for reference. A10130401

- Knowing the Importance of Understanding and Adjusting One's Own Communication Method

See things from other people's points of view. During communication, we often think from our own perspective instead of others' points of view. This will give rise to unnecessary tension and conflicts. It is easier said than done, but it is something we must learn. A10270202

For cross-cultural communication and interaction, the hardest part, I think, is communication ...if we cling onto our own ways to communicate with another person it will sometimes produce an adverse effect. A11030103

4.4.4 Discovering Meanings through Cross-Cultural Actions

- Noticing the Importance of Team Work

The biggest reward is teamwork and communication among members. It takes a huge effort to produce a video. That is why everyone is like an important screw in a machine. A12292403

- Gaining Willingness to Voice Out for Others Owing to Understanding

I think it is inappropriate to discriminate against foreign workers. The reason that they left home and traveled all the way to Taiwan was to work and earn money. We should treat them with empathy, not discrimination. A10131603

Today I have learnt that new inhabitants have put considerable effort and care into looking after their family and children. They all have their own stories and difficulties. We must learn about their efforts, instead of continuing to discriminate against them. A10133104

- Making Efforts to Overcome Difficulties in Cross-cultural Communication

I think the most difficult part was conducting spoken interviews because the differences in language led to language barrier...Gradually I could teach him my language, or even exchange our cultures, which is the best kind of cross-cultural communication. A10271803

The most important parts in cross-cultural communication are languages and the motivation to keep learning... When we encounter people from other cultures we can realize or perceive the differences among people or countries. A10272402

The second focus is the changes in the participants' cross-cultural communication competencies during their learning experience. With the improvement of their ability to identify media representation, as mentioned previously, they realized how their own values differ from those of other people or society. Thus, they discovered society's bias or discrimination against certain ethnic groups while reviewing their own viewpoints about those groups. They could better understand the plights of various ethnic groups as they heard their stories and interacted and conducted hands-on interviews with them. Through interaction and new information, students became empathetic toward ethnic groups and adjusted their own viewpoints on different things, consequently adopting different perspectives in perception and reflection. During the class, having understood that different countries have distinctive ways of communication and expression, the students found several challenges in cross-cultural communication. Subsequently, they indicated a golden rule in good communication - to understand each other and see things from another person's perspective. This also allowed them to perceive the importance of self-adjustment during cross-cultural communication. During the team project of interviewing new inhabitants and exercising citizen journalism via video production, the participants accidentally conceived meanings from cross-cultural actions. For example, they experienced the hardship and joy of team cooperation; they understood the feelings of 
the new inhabitants and developed a willingness to speak for their plight; they also discovered that despite the numerous obstacles in cross-cultural communication, communication barriers could be overcome with a passionate and diligent heart.

\subsection{Changes in Cognition, Attitude, and Behavior: Internalize and Actualize}

4.5.1 The Transformation of Competencies in Media Representation from Speculation to Practice

- Honing Skills in Speculation and Interpretation of the Media

The course opened my eyes on how to reflect on the news media. Not all new reports deliver the truth. We must be able to distinguish right and wrong and avoid being blinded to the truth. $\mathrm{C} 10041802$

The lecture on Islam gave me an impression that almost all Taiwanese media see countries in the Middle East having an inclination toward European and American cultures. There are both good and bad people in every culture. A10270302

- Changing the Old Way of Thinking Toward the Media

Contrary to our traditional way of thinking, the reason why new-inhabitant women have married Taiwanese is not money. In fact, they are also here to pursue their happiness. A11241204

Most of us have gained some impressions on other countries and their customs from the media, but we do not actually have any true understanding of them. That is why we have developed certain stereotypes. A10132101

- Utilizing the Media to Speak Out for Others and Change Society

We made use of what we learnt about media to speak out for new inhabitants. Through our work, we want to let more people hear the new inhabitants' unspoken thoughts. C10042501

Media production can help citizens understand many issues in their surroundings, such as problems needing improvement in living environments. It can bring changes by uniting a collective effort. A12080604

4.5.2 Improving Cross-cultural Communication Competencies, from Understanding to Actions

- Improving Cross-cultural Acceptance and Sensitivity

I can better relate to the feelings of the new inhabitant women and feel empathetic towards them...Not everyone came for money. This sharing has given me a deeper understanding of Vietnam. A11242304

- Changing Personal Opinions and Attitude Toward Certain Groups

From now on, whenever I see a new inhabitant who cannot communicate with other people fluently I will help her definitely, because she does not know anything here very well, and languages could also lead to misunderstanding. C10043303

This filming activity has refreshed my opinions on new inhabitants who are unlike the negative images outlined in the news. A12291602

- Learning from Cross-cultural Interaction and Applying the Results to Real Life

I have learnt how to listen to their stories in greater depth, and expand this spirit and attitude further to other similarly underprivileged groups. C11172902

I felt touched when I was chatting with the new inhabitant women...It has increased my knowledge about these new inhabitants and changed me so that I won't easily accept the labels of those I do not know well. C10042403

After an entire semester of learning, the participants underwent qualitative changes in their cognition, attitude, and behavior regarding their ability to speculate about the media and their cross-cultural communication competencies. The first part concerned the transformation of the competencies in media representation. The course honed their skills in speculation and interpretation of the media. They could establish and visualize their own set of standards in perceiving the media, thereby adjusting their way of thinking toward it. Simultaneously, as they witnessed the abuse and advantages of the media, they also developed the idea and attitude of utilizing it to overturn the media and influence society. Thus, they were willing to speak out for the underprivileged and daily issues with actions, actualizing the spirit of citizen journalism. The second part concerns the participants' improvement in cross-cultural communication competencies. Understanding and accepting different cultural information broadened their horizons, while expanding their acceptance and sensitivity toward different ethnic groups and 
cultures. Meanwhile, their partial thoughts and attitude toward certain ethnic groups changed as well. These changes preliminarily realized the ideals of Chen (2003), Imel (1998), and Taylor and Henao (2006) regarding cross-cultural understanding and learning. The students could then adopt diverse perspectives to observe and learn from the merits of various ethnic groups and their cultures, in turn applying these good qualities to daily life for stimulating changes in cross-cultural communication actions.

\subsection{Strategy Review of the Design of Cross-Cultural/Media Literacy Course}

\subsubsection{Learning Techniques in New Media Tools and their Impact on Civic Participation}

The students had to become familiar with new inhabitants in a short amount of time, but they had limited knowledge of the community and insufficient experience of interviewing strangers. Therefore, oftentimes, their interaction and interview skills required improvement. As they were often unable to harness skills in interacting with the interviewees, the news information they gathered was not sufficiently in-depth. They also encountered several technical problems in presenting their work through videos or media. However, this study noted that the teacher would still guide students appropriately concerning these problems during the learning process. For instance, she allowed access to her Facebook Inbox for consultation, and continuously made consultation appointments with students and conducted group discussions. She also included ancillary encouragement and reward measures so that students could complete their assignments efficiently, despite their earlier inadequate skills in conducting interviews or producing videos (Hsu, 2008b, 2009a). More importantly, when the students displayed their work on the citizen journalism platform, considering the media techniques they had acquired during the process, most of them felt that their skills and actions could indeed transform certain pre-existing values. This outcome is consistent with the joy of integrating experimental knowledge with experience as proposed by Huang (2003). The process of media production also allows students to construct their own understanding through deconstructing and reconstructing texts, thus liberating them from the dominance of the media (Freire, 2003).

Therefore, it is clear that, with the aid of the teacher's constant encouragement and assistance, learning techniques of media access in media literacy courses can indeed enhance students' overall learning outcome. Thus, students can be freed from media dominance, construct their understanding, and eventually speak out for others using actions to fulfill the purpose of media access also called civic participation as Liu (2015) mentioned. Although there was room for improvement in the students' final work and their competencies of using tools, as in uploading their work to the citizen journalism platform, this study achieved an indicative success in civic participation and actions, fostering of cross-cultural and media literacy, and development of deconstructing competencies.

4.6.2 Changes in Cognition, Attitude, and Behavior with Limited Continuous Action Strength

Scholars (Chen, 2003; Imel, 1998; Taylor \& Henao, 2006) indicated that an essential aspect in reinforcing the cross-cultural learning process is to shift from the "object" to the "subject" position and from the classroom to the outside world. Although playing the role of journalists, students in this course gradually acquired empathy, which is highlighted in cross-cultural literacy, from their objective perspective and subjective experience as well as their hands-on practice. This occurred through their first-hand experience in realizing, questioning, and reflecting, especially induced by the cross-cultural knowledge taught in class and conversations with the teacher, which improved students' cognition and attitude about cross-cultural literacy more significantly. According to previous empirical research results (Ametrano, Callaway, \& Stickel, 2002), basic core values, competencies, and literacy affect the values, beliefs, and living world of teachers and students. It is especially true for this course, which concerned cross-cultural/media literacy and included community practices, leveraging citizens' action strength through media tools. Hence, it effectively strengthened the learners' competencies in making reflections and critical judgements. Through their experience of participating in this subject-based course, learners achieved the two goals of media literacy education stressed by Freire (2003) and Lu and Pai (2012), that is, liberation and empowerment.

In terms of cognition, attitude, and behavior, this course design with students as the subjects proved what critical pedagogy scholars Freire (1989) and Barnett (1997) emphasized-that learning in cognition and attitude must eventually generate actions to qualify as an actualization of the action strength of critical judgements. Indeed, cognition, attitude, and actions are interconnected and work as one. During discussion, the students constantly answered the teacher's questions, interacting with her. This process was training the students' logic and integration skills in critical thinking, influencing them subtly and activating their thinking in cross-cultural/media literacy. However, the students' learning outcomes and growth differed, owing to their differences in competencies and prior life experiences. This study noted that since the students' learning was limited by the education system, this learning mode was effective under the teacher's guidance in actualizing the action strength of critical thinking. 
Nevertheless, it was also noted that after course completion, the students generally demonstrated a low incentive to truly care about public interest and take continuous actions accordingly. As Huang (2003) observed, students found it joyful that their actions might be able to change the pre-existing values and bias in the living world, or their relationship with the new inhabitants. They also deemed it meaningful to upload and share their work on public platforms, as required by the course assignments. However, away from the teacher, classroom, and education system, students should be able to engage actively in public affairs and focus on new inhabitants' development. The study found that after the course, there was limited action strength of actual participation with time and effort, or even in different life experience and living worlds of individuals.

\section{Conclusions and Suggestions}

This study employed a course that taught cross-cultural/media literacy with media production and participation techniques in the citizen journalism platform, and practices at different stages such as field interviews, filming, and editing videos, group discussions and sharing of final work. It found that students' cognition, attitude, and behavior were different from their original subjective experience as the former changed from partial and stereotypical to diverse. During their interaction with the new inhabitants in the community, students, as the subjects of practice, appeared to be constantly reflecting, adjusting, and reviewing themselves and their rational or contradictory experiences in the past. Their original cognition and attitude were reinforced subconsciously or even altered. Embodying the concept of relative subjectivity in knowledge construction, this method is evidently effective in teaching both cross-cultural understanding and communication.

However, as this course focused on developing knowledge and thinking in media representation/cross-cultural literacy, it was challenging to spend only four to five weeks out of 18 in teaching the students media access techniques such as interviewing and practical skills in filming and video-editing. The students were easily frustrated as they were unfamiliar with the techniques and faced constant difficulties. Therefore, it is suggested that in the future, the course can be divided over two consecutive semesters. The first semester can ensure students grasp practical media skills, while the second semester can focus on connecting media literacy with cross-cultural understanding and communication. This can avert superficiality in the values, beliefs, and cultural patterns and, thus, in the overall course.

Finally, in terms of the research limitations, the problems caused by new immigrants in Taiwan concern structural factors primarily. The course design aimed at improving students' critical judgements and literacy, instead of performing techniques. Their transition from traditional passive receptors to active creators of messages, achieved the overall teaching objective and efficacy. However, most students lingered on the message production and transmission stages owing to their inept production skills. For a deeper connection to life experience, a follow-up study must be conducted on the changes in the students' life experiences and practices brought by interaction with new inhabitants after the course. Therefore, the first-hand interaction should last for a long time, assume more dimensions, and be recorded for a comparison with the follow-up research data and the course, thus more comprehensively representing the efficacy and influence of implementing a course that considers students as the subjects.

\section{References}

Ametrano, I. M., Callaway, Y. C., \& Stickel, S. A. (2002). Multicultural infusion in the counselor education curriculum: A preliminary analysis (ERIC Document Reproduction Service No. ED 465 297).

Barnett, W. P. (1997). The dynamics of competitive intensity. Administrative Science Quarterly, 42, 128-160. https://doi.org/10.2307/2393811

Bazalgette, C. (1997). An agenda for the second phase of media literacy development. In R. Kubey (Ed.), Current perspectives. Information and behavior: Vol. 6. Media literacy in the information age (pp. 69-78). New Brunswick, NJ: Transaction.

Buckingham, D. (2003). Media education and the end of the critical consumer. Harvard Educational Review, 73(3), 309-327. https://doi.org/10.17763/haer.73.3.c149w3g81t381p67

Buckingham, D. (Ed). (1990). Watching media learning: Making sense of media education. Basingstoke, UK: Falmer.

Chen, G. (2003). Intercultural communication. Taipei City: Five South.

Chen, M. (2002). Media reproduction and identity politics. 2002 Annual Conference and Seminar of Chinese Society of Communication.

Dong, S. (2004). A probe into the necessity and operational idea of "media reading" general course in university. 
Practice common sense, 2, 1-25.

European Commission. (2004). Implementation of the Education and Training 2010 Work Programme. Key competences for lifelong learning: A European reference framework. Retrieved March 5, 2011, from http://ec.europa.eu/education/policies/2010/doc/basicframe.pdf

Gao, J. (1996). Qualitative research methodology. Taipei: the teacher book court.

Hong, G. Z. (2005). Practice of community action research.

Huang, W. (2003). School outside the window. Taipei City: Left Bank.

Imel, S. (1998). Distance education. Myths and realities (ED 399 383). Columbus, OH: ERIC Clearinghouse on Adult, Career, and Vocational Education.

Liu, H. (2015). From media literacy to new quality: On the change of teaching strategy and epistemology. Chinese spread.

Lu, J., \& Pai, Y. (2012). Reconsideration and prospect of media literacy education and curriculum practice. Courses and Teaching, 15(1), 1-34.

Mao, G., \& Chang, Y. (2006). Research on the action of constructing affection education with positive psychology. Journal of Teachers College: Education.

Masterman, L. (1985). Teaching the media. London: Routledge.

Masterman, L. (1997). A rationale for media education. In R. Kubey (Ed.), Current perspectives. Information and behavior: Vol. 6. Media literacy in the information age (pp. 15-68). New Brunswick, NJ: Transaction.

Miles, M., \& Huberman, A. M. (1994). Qualitative data analysis. Thousand Oaks, CA: Sage Publications.

National Science Research Program Report (No. NSC96-2413-H-260-013). Taipei City: Executive Yuan.

Pan, S. (2003). Qualitative research: Theory and application. Taipei: Psychology.

Taylor, J. A., \& Henao, V. M. (2006). Intercultural competence without international experience. Retrieved March 5, 2011, from http://nationaleltconference.org/resources/2006/Josephine_Taylor_Vivian_Morales_ Intercultural_Competence.pdf

Wober, J. M., \& Gunter, B. (1988). Television and social control. Aldershot, UK: Avebury.

Xie, S. M. (2010). Translation and cross-cultural communication. Journal of the European Languages, 3, 147-163.

Xu, M. (2008). A study on the design strategy of integrated curriculum of community college. National Science Council of the Executive Yuan.

Xu, M. (2009). A Comparative Study on the Design of Integrative Curriculum in Community Universities: A Comparative Study of Keelung and. Journal of Educational Science Research, 54(3), 51-82.

Yin, R. K. (2009). Case study research: Design and methods (4th ed.). Thousand Oaks, CA: Sage Publications.

Zheng, M. (2012). Critical approach to media literacy. Courses and Teaching, 15(1), 67-90.

\section{Copyrights}

Copyright for this article is retained by the author(s), with first publication rights granted to the journal.

This is an open-access article distributed under the terms and conditions of the Creative Commons Attribution license (http://creativecommons.org/licenses/by/4.0/). 